\title{
Editorial
}

\section{Cell Biology Education}

\section{Samuel Ward}

\author{
Department of Molecular and Cellular Biology, University of Arizona, Tucson, Arizona 85721
}

\begin{abstract}
We have not been very systematic about our quest to improve teaching, even though we value it highly and frequently do well at it. I am struck, for example, by the lack of conversation about what pedagogy means, and what makes it successful. It is our profession, yet it is mysteriously absent from our professional discourse. Here we are, engaged in an activity that is vital to ourselves, our students, and our public-yet we speak of how to do it, if at all, as though it had no data base, lacked a history, and offered no innovative challenges. (Donald Kennedy, 1990, Stanford President's Address: Stanford in Its Second Century)
\end{abstract}

The first issue of the American Society of Cell Biology's (ASCB's) new education journal, Cell Biology Education (CBE), is available online at http://www.cellbioed.org and through the National Library of Medicine's PubMed Central, at http://www.pubmedcentral.nih.gov. The journal has three major goals: to provide an opportunity for scientists and others to publish high-quality, peer-reviewed, educational scholarship of interest of ASCB members; to provide a forum for discussion of educational issues; and to promote recognition and reward for educational scholarship. The idea and plans to implement such a journal came from the ASCB Education Committee and reflect the ASCB's long-standing commitment to improving science education.

We hope that the journal will help to address the paradox posed by Donald Kennedy above-that discussion of pedagogy, teaching, and education are too often missing from our professional discourse, particularly in our research universities. Cell Biology Education will provide a forum for such discourse and a means to communicate our educational experience and knowledge within the ASCB and to the larger scientific and education communities. The Editorial Board guiding the development of $C B E$ includes biology and education scholars from diverse institutions. Although the journal is sponsored by ASCB, we welcome articles on education in related disciplines, including physics, chemistry, mathematics, and engineering, because these are now more essential than ever to biology research and effective interdisciplinary education is challenging. Although we expect an emphasis on undergraduate, graduate and medical education, we welcome educational articles related to all levels of education $\mathrm{K}-20+$ and to diverse institutions, including science museums.

DOI: $10.1187 /$ cbe.02-04-0012

Corresponding author. Email: samward@u.arizona.edu.
CBE will publish several kinds of articles and will have regular columns. Articles will include science education research articles, focused on theoretically grounded questions, and utilizing either quantitative or qualitative methods of analysis as well as more descriptive articles detailing educational innovations-e.g., inquiry laboratory courses, webbased courses, and interdisciplinary curricula. These must be "tried and tested" and should include some level of assessment and references to related literature. There will also be invited and submitted reviews of current or historical issues in science education, on science policy related to science education, and reviews of books and web-based educational materials. Regular columns will be on technology and education, reviews of videos for teaching, and reports from the ASCB Education Committee. $C B E$ will be published electronically quarterly and the website will include opportunities for electronic discussion of published articles.

Educational scholarship offers significant challenges that are different in many ways from cell biology research. Teaching has a larger personal component, and success is difficult to measure and hard to transfer to others because it is often so context dependent. This difficulty of transfer makes a big difference from cell biology research, where the central criterion for validity is reproducibility by others. Valid assessment of educational innovations and accomplishments is challenging because variables are hard to control, and measuring changes in students' knowledge, attitudes, and behaviors is difficult particularly over the long term. The first issue of $C B E$ includes an article on the assessment of student learning (Sundberg, 2002), which reviews various ways to carry out valid educational assessment and emphasizes our responsibility as scholars to assess our own teaching to improve it.

Perhaps the most widespread barrier to improving science teaching, at least at many research universities, is the belief that teaching is not recognized and rewarded. For example, as Derek Bok stated when he was president of Harvard University,

A serious attempt to balance the legitimate claims of teaching and research must begin by understanding something of the incentives that inspire each type of activity. Both pursuits hold great intrinsic interest, just as both can entail much drudgery and frustration. In contrast, the extrinsic incentives and rewards are almost always more powerful for research than they are for teaching.... The imbalance also stems from the fact that research can be studied carefully and communicated to 
a very wide audience. (Derek Bok, 1988, President's Address to the Harvard Board of Overseers)

Many institutions and funding agencies have worked to address this imbalance, particularly the National Science Foundation, and in the biological sciences, the Howard Hughes Medical Institute. We are honored that the Howard
Hughes Medical Institute has provided a grant to help support $C B E$. We hope that with their support, and the support from many ASCB members committed to both research and teaching, $C B E$ can help to address some of this imbalance by providing a way that successful and innovative teaching can be recognized and communicated to a wider audience. 